\title{
Study on Effective Fusion of the Traditional Chinese Culture and Graphic Design
}

\author{
Saihua Xu \\ School of Information, Nanchang Institute of science \& Technology, Nanchang, 330108, China \\ xusaihuapaper@163.com
}

Keywords: Traditional Chinese Culture; Graphic Design; Effective Fusion.

\begin{abstract}
This paper first interprets the concept of the traditional Chinese culture and modern graphic design, and then discusses effective fusion of the traditional Chinese culture and modern graphic design and its advantages through analyzing the application of the traditional culture in graphic design In addition, it points out that the designer should treat correctly the traditional culture and apply in it. And it also requires the designer to get to know the profound connotation of traditional Chinese culture and national emotion idea.
\end{abstract}

\section{Introduction}

The traditional culture is radiating out the dense aromas in the changes of society. The traditional Chinese culture was able to keep unchanging and increasingly extensive and profound because it can get the advantages without suffering the disadvantages and constantly enrich its connotation in different ages. In the 21st century today, when the graphic design has become indispensable cultural technology to modern humans, how can the traditional Chinese culture to embody its humanistic value? How can the modern graphic design embody the traditional Chinese culture breath?

\section{The traditional Chinese Culture}

The traditional Chinese culture has a long history and is profound, but the unique national character expresses the different aesthetic taste and aesthetic interest of all nationalities in the People's Republic of China. The traditional Chinese culture is a unique school of its own in the world, which deserves our full respect and exploration [1-2]. In every period of history, the traditional Chinese culture has its own special cultural connotation and cultural characteristics, the cultural element of its contain the abundant and complicated variable contents. So the traditional Chinese culture has constantly developed and made perfect in practice, get the advantages without suffering the disadvantages. Nowadays, in the traditional Chinese culture, the Xiao Zhuan embodies the Chinese culture breath, the dragon represents the cultural beliefs of the Chinese nation, and plum flower shows the Chinese moral integrity in modern life. Until now, the Chinese people have remained a profound and have special liking feelings about the traditional Chinese culture.

\section{The Discusses of Modern Graphic Design Concept}

\subsection{The Beautiful Idea of the Graphic Design}

It is very important to understand properly beautiful idea. In graphic design, if the form and expressed content of the graphic design cannot show out the word "beauty", it will become a failure graphic design [3]. Among different areas, different people have different understand of beauty. But for the designer, it is very important to understand correctly beautiful idea of the graphic design. Therefore, the designer not only needs to have general understanding of beauty, but also constantly cultivate their professional understanding of beauty. Only then can the designer correctly grasp the total direction of its design, and create a creative subject, which is full of fashion, connotation and acceptance. 


\subsection{The Graphic Design Needs Unique style}

With the development of the era and the continuous improvement of people's living standard, people's aesthetic demand is also becoming increasingly "harsh". In order to avoid appearing of people's aesthetic fatigue, and attract people's attention, the ideals of designers should need to have a unique characteristic. And only the design style have unique characteristic. In the fierce market competition, only can the graphic design with unique style get the existence and development of space in the market with fierce competition [4-5]. Taking a broad view, the ideas of the graphic design drastically impact our visual appreciation, makes people feel the design connotation of design. In the design of the changing times, the successful graphic design needs to have a creative idea of graphic design, form an accepted and unique style.

\subsection{The Graphic Design Needs to Catch up with the Times}

Once upon a time, because the most graphic design only depend on artificial painting and simple computer design to finish the work, so the design work has been seriously restricted [6]. However, with the development of era and improvement of the science \& technology, all kinds of design software brought about previous sly unimagined experience and direction to the designer. The abundant theme ideas of modern graphic design were embodied in modern graphic design by using the convenience of design tools. The some limitation of graphic design were broken, which enables people to enjoy a more abundant and vivid creative design of the visual feast. In addition, with the development of the society, people's aesthetic requirements have also been changed. So the designers need to walk in world front and theme intention of their design need to keep the pace with the times.

\subsection{The Graphic Design Needs Diversified Development}

In the impact of diversified culture and thoughts, the theme originality of graphic design has to follow the pace of change. Therefore, in graphic design, the expression of graphic design theme originality should express as broad as possible, and strive to contain new elements as much as possible. In addition, the theme originality of design should be also oriented to much wider population. The design works would be accepted and welcomed more people than ever. As is known to all, the people of the different cultural connotation and ages have different views on cognition degree of design idea. And different people have different view on cultural connotation of graphic design in the graphic design. In order to achieve successful and effective advertising effect, the graphic design theme originality needs to the trend of diversified development.

\subsection{The Graphic Design Needs to Follow the Need of Moral Ethics}

With the continuous development of society and the progress of times, the requirement of the graphic design will become more and more stringent. In order to meet the need of constantly improved aesthetic and emotion, and adapt to the tide of the era, many graphic designers have seek for appearance of design product persistently, but ignored the social moral and ethical requirements. Because all design works serve mankind, design idea should be more human-oriented, and all design ideas should be developed around needs of the people, which follow humanism design. Only under the premise of following moral and ethical requirements, the graphic design can give their creative theme more deep inner meaning. And the graphic design can break through blindness of design revision and ensure harmonious with works and human perception to achieve the coordination, so as to make the social ideological follow the development trend of more humanity.

\section{The Application of Traditional Chinese Culture in the Graphic Design}

Modern graphic design is very dependent on inheriting and application of traditional Chinese culture, it is also an important research subject for modern graphic designer that how to learn to add traditional cultural elements to design idea. For the graphic designer, it is most taboo to randomly misappropriate and simply inherits traditional Chinese culture in modern graphic design and the combination of traditional culture. By doing that, these graphic design works may have lost richness of its connotation and uniqueness of era. But design works cannot mindlessly ape and plagiarize the Western culture in accordance with reflecting era character of design works. 
When designs work of the graphic designer need to inherit the traditional culture, the graphic designer first needs absorb the essence of traditional culture and understand the traditional cultural connotation, and then renovate design works by using the modern design method, so as to make the humanistic value of traditional culture achieve advertised publicity effect. In graphic design, the graphic designer must learn how to get the advantages without suffering the disadvantages. Nowadays, people are paying more and more attention to remain and develop traditional Chinese culture. In modern social life, we can found that many design works mix many traditional Chinese culture, such as Bank of China sign, which expresses idea of financing institution. The sign of bank shows obviously that signboard of bank. The graphic design of filling with traditional cultural atmosphere combines traditional Chinese culture and modern design idea, which is a much successful design work.

In this highly modern and informative integration era, the life style of global process makes the thoughts and concepts of Chinese people huge diversification. However, under the assault from Western thoughts of art idea and design, the Chinese graphic designer has to face up to the cultural differences between east and west. Thus, more and more graphic designers pay close attention to the traditional Chinese culture. In fact, for thousands of years, cultural characteristic of numerous nations form richness, peculiarity and difference of traditional Chinese culture. The different nation constructs different aesthetic taste and aesthetic pursuit. But the national culture has also commonality in using group, which can attain goal of cultural messages. The graphic design of combining with the traditional culture can show profound national emotions and custom. In addition, it can also express appetency and produce emotion sympathetic chord, so as to get easily people's acceptance. If the graphic design is short of traditional culture, it only can reflect the characteristics of times. And theme ideas and forms of the graphic design work will be limited because of emotional basis, which may be foreign to the graphic design in cultural inherited emotion. For this reason, the modern graphic designer should retain application of traditional Chinese culture in the graphic design, so as to achieve function of conveying messages. In the actual daily life, the graphic design of containing Chinese traditional culture can be seen everywhere, so to say, if the graphic design left traditional Chinese culture and the graphic design would like water without a source, and a tree without roots.

\section{The advantages of combining the traditional Chinese culture with the graphic design}

The traditional Chinese culture shows it has abundant connotation and long national feelings, which can give people intimacy and make people enhance receptivity and identification to thing. Therefore, if the graphic designer can combine the Chinese nation traditional culture and national elements in the graphic design, which can easily inspire the audience's resonance and love feelings, so as to achieve the goal of advertising. In addition, the graphic design work of mixing the traditional cultural feelings can fill the creative theme without contents, and also possess the design idea of filling with emotional feelings of emotional culture. The graphic designer combines the traditional Chinese culture with the national elements in the graphic design, which broadens design idea of the graphic design work in some certain. Mr. Lu Xun said, "What is of national is of international". The design work with the mark of the Chinese nation traditional culture makes the Chinese graphic design get a place in the world. Because of the design work has the features of unique national feelings, which make the Chinese people increase a proud feeling. For the graphic design, it needs to combine the Chinese traditional culture with the national elements in the creative theme, and learn enough nutrition, the Chinese nation's traditional culture and aesthetic temperament and interest, Chinese traditional culture. Only in that way will the graphic design can stand in the east of the world, and move bravely ahead. 


\section{Summary}

Under the background of globalization, all kinds of foreign aesthetic pursuit and design concept have impact on people's aesthetic values and artistic concept. But in the graphic design of our country, the graphic designer aggressively over-pursue novel work and creative theme, which easily cause them to lose the application of traditional Chinese culture in the pace of progress. In addition, because some graphic designers have a blind worship for foreign design idea and art culture, our traditional advantages easily have long been shelved, or even completely forgotten. The traditional Chinese culture contains abundant connotation and its cultural value, which become inexhaustible design resource and source of design ideas of the graphic designers. Therefore, it is very important for the graphic designer to treat correctly the traditional Chinese culture and develop it better.

\section{References}

[1]. ZHANG X Q and CHEN H. On the Innovation Design of Chinese Traditional Pattern. Anhui Literature, Vol. 9 (2009) No.20:77-78.

[2]. PENG F Z. Introduction to Chinese Traditional Culture, Beijing University Press, Vol. 10 (2011) No.4: 15-16.

[3]. ZHANG L L. Application of Traditional cultural symbols in Modern Graphic Design. Dissertation for Master degree, Hebei Normal University, China. P.30-38.

[4]. LIU Y L. Study on Application of Traditional Chinese Culture Elements in Modern Graphic Design. East West South North· educational observation, Vol.9 (2011) No.14: 65-66.

[5]. C Q and XU J D. Study on Application of Traditional Chinese Culture Elements in Modern Graphic Design. Art Science and Technology, Vol.26 (2013) No.1: 113-114.

[6]. BI F X. Application of Traditional Chinese Culture Elements in packing Design. Packing Engineering, Vol. 18 (2010) No.10: 11-12. 